\title{
Successful management of a near miss case of eclampsia with intracranial haemorrhage requiring craniotomy
}

\author{
Aditi P. Kaundinya*, Meena N. Satia, V. R. Badhwar
}

Department of Obstetrics and Gynecology, D. Y. Patil Hospital and Research Centre, Navi Mumbai, Maharashtra, India

Received: 28 June 2019

Accepted: 25 October 2019

*Correspondence:

Dr. Aditi P. Kaundinya,

E-mail: aditikaundinya@gmail.com

Copyright: (c) the author(s), publisher and licensee Medip Academy. This is an open-access article distributed under the terms of the Creative Commons Attribution Non-Commercial License, which permits unrestricted non-commercial use, distribution, and reproduction in any medium, provided the original work is properly cited.

\begin{abstract}
Large population-based studies on stroke report that intracerebral haemorrhage is rare in young women however it is a grave and disturbing complication of pregnancy. Preeclampsia is usually clinically silent, but may cause symptoms of neurological dysfunction such as headache, visual disturbances and impairment of consciousness. Eclampsia is in the occurrence of seizures in the context of preeclampsia and is often, but not always, preceded by the above neurological symptoms. Most published data support the view that preeclampsia and eclampsia are important causative factors for pregnancy related ICH. Sparse data is available with respect to the management of such cases. Identification of near miss cases is an important step in reducing mortality. Herein we report a near miss case of eclampsia with intracranial haemorrhage requiring craniotomy.
\end{abstract}

Keywords: Craniotomy, Eclampsia, Intracranial haemorrhage, Near miss, Preeclampsia

\section{INTRODUCTION}

The incidence of cerebrovascular accident in pregnancy including superior sagittal sinus thrombosis varies from 1 in 600 pregnancies. ${ }^{1}$ Intracranial haemorrhage (ICH) accounts for $5 \%-12 \%$ of all maternal deaths. Preeclampsia/eclampsia is one of the autonomous risk factors for pregnancy associated $\mathrm{ICH} .{ }^{2}$ Possible adverse effects of preeclampsia on systemic vessels include endothelial dysfunction, microangiopathy and vasospasm. ${ }^{2}$ Additionally, high blood pressure results in damage the vessel walls which results in rupture and bleeding. ${ }^{2}$ Concurrent ICH maybe the end stage manifestation of preeclampsia. ${ }^{2}$ Patients with pregnancy associated ICH have guarded prognosis for mother and foetus compared with ICH associated with other etiologies. $^{3} \quad$ Coagulopathies, cerebrovascular malformations, tobacco abuse/ dependence are other etiological factors responsible for $\mathrm{ICH}^{4}{ }^{4}$ In our case patient had pre-eclampsia prior to the occurrence of intracranial haemorrhage, there is sparse data reporting such cases and the absence of standard management guidelines makes managing such cases challenging. According to WHO guidelines maternal near miss can be defined as a woman who nearly died but was saved from a complication that was detected during pregnancy, childbirth, or puerperium and specific criteria for identification of the same have to be followed. ${ }^{5}$ This case fulfilled the near miss criteria, identification of such near miss cases helps to identify lacunae in maternal health care and can thus help in reducing maternal mortality.

\section{CASE REPORT}

A 30-year-old primigravida presented to the emergency department of our hospital with severe preeclampsia at 38 
weeks of gestation. Antenatally she was following up at a private hospital where in the first high blood pressure reading of 150/100 was noted following which she was referred. She did not have any other comorbidities. At admission patient was conscious well oriented in time place and person with a GCS score of 12, BP was $160 / 110 \mathrm{~mm} \mathrm{Hg}$ and urine showed albuminuria (4+ on dipstick), LFT's showed elevated liver enzymes and low platelet count (80000), renal parameters were normal. In view of severe preeclampsia with HELLP syndrome patient was given prophylactic magnesium sulphate full loading dose (Pritchard's regime) however within an hour of this injection patient had a generalized tonic clonic convulsion associated with upturning of eyeballs and frothing at mouth. Her airway was stabilized, anticonvulsants were administered, patient's vital parameters and foetal heart was monitored, however in the course of which there was acute foetal distress in view of which she was prepared for emergency caesarean section. Patient was drowsy and disoriented following the convulsion. She had another similar convulsion prior to being shifted for the caesarean section. LSCS was done under general anaesthesia,

She delivered a healthy baby boy 3 kilograms with no intra operative complications. Patient was shifted to the ICU on ventillatory support post operatively.

Post operatively there was a drop in the haemoglobin (8 $\mathrm{g} \%$ ) and a further drop in the platelet count (60000), it was also observed that the patient was having hemiparesis of both lower limbs, CT scan done which showed a large hyper dense haemorrhage in the right parietal lobe measuring $6 * 4.6 \mathrm{~cm}$ with significant surrounding oedema, mass effect was seen in the form of effacement of adjacent sulci and compression of right lateral ventricle with midline shift and haemorrhage extending into all ventricles. Neurosurgery opinion was sorted following which an emergency craniotomy was performed to evacuate the haemorrhage after replenishing her with 2 units of packed cell and platelet concentrates.

Following craniotomy her general condition and neurological status gradually improved. On the third postoperative day she was extubated and thereafter shifted to the post-operative ward. Her liver function tests and platelet count also reverted back to normal. Blood pressure was also adequately She was given physiotherapy and gradually her power in both limbs also showed remarkable improvement. Subsequently she was discharged on $20^{\text {th }}$ post-operative day with power in both limbs improving to grade 3 and no other neurological deficit.

\section{DISCUSSION}

CVA during pregnancy is an uncommon disease but it is significant as it has an alarming fatality of up to $20 \% .^{6}$ Wittin et al, have reported $24 \mathrm{CVA}$ disorders in antenatal period out of which 6 patients were diagnosed as ICH. ${ }^{7}$
Intracerebral haemorrhages have been found in up to $40 \%$ of patients with eclampsia in autopsy series. Most cases of $\mathrm{ICH}$ in pregnant woman are from vascular malformations such as arteriovenous malformations, aneurysms or Moya Moya disease. Less often but equally devastating are spontaneous ICH. Preeclampsia and other pregnancy related hypertensive disorders are common comorbidities. $^{8}$ Kittner et al, reported $14 \%$ of patients suffering from ICH with either eclampsia /preeclampsia, Sharshar et al attributed $44 \%$ of ICH to eclampsia in their cohort. ${ }^{6,9}$

Contrary to the data published, our patient did not have any of the other known risk factors for $\mathrm{ICH}$ such as maternal age > 35 years, African-American race, tobacco dependence substance abuse, coagulopathy or previous history of preeclampsia/eclampsia. ${ }^{10,11}$ However our patient had preeclampsia which is an independent risk factor associated with $\mathrm{ICH}^{9}{ }^{9}$ Also our patient was of Indian origin and there are reports indicating a higher incidence of haemorrhagic stroke in Asian women as compared to Caucasian patients, most commonly occurring in the postpartum stage, as was seen in our case which presented in the immediate postpartum period. ${ }^{12}$ The incidence of pregnancy associated ICH is highest during the postpartum period, rapid changes of hormonal and haemodynamic changes during the post-partum period may promote the development of $\mathrm{ICH}$ due to effects on coagulation and blood vessel walls. ${ }^{10}$ Nevertheless, recent studies have shown that ICH primarily occurred during the antepartum period, especially the third trimester. ${ }^{3}$

The presentation and clinical features of stroke in pregnancy can be variable and diverse classical clinical presentation of ICH includes varied forms of photophobia, convulsions, temporary unconsciousness as well as neck stiffness.9,13 Our patient presented with convulsions antenatally and left sided hemiparesis following LSCS, whether the convulsions were because of eclampsia or ICH is unknown as CT scan was not performed antenatally.

Management of intracerebral haemorrhage follows standard neurosurgical principles. Management needs to be individualized based on the maternal general condition and the gestational age of the pregnancy. Surgical evacuation of clot is indicated if there is declining consciousness or worsening neurological deficit. A nonoperative approach is appropriate in case of devastating haemorrhage that is non recoverable, although surgery might be considered in an effort to prolong the life of the mother in the interest of the foetus. The role of surgery is unclear in other cases. ${ }^{14}$ A large trial comparing early surgery with medical management in the treatment of primary ICH did not support the use of surgery in this intermediate group. ${ }^{14}$ This trial shouldn't be interpreted as demonstrating that surgery has no role it only demonstrates that in cases where the role of surgery is unclear, there is no benefit from early surgical 
intervention. In a study conducted by Liang et al, they found that prognosis of mother and foetus in preeclampsia group were poorer as compared to $\mathrm{ICH}$ with other aetiology with greater maternal and neonatal mortality and lower APGAR scores of the neonates. ${ }^{2}$ They found no difference in the outcomes between patients managed conservatively versus those managed surgically which suggested that the type of treatment doesn't affect prognosis. ${ }^{2}$ This was in contrast with a study conducted by Dias and Sekhar who reported that early surgical management of aneurysms during pregnancy and puerperium was associated with lower maternal death $(63 \%$ versus $11 \%)$ and foetal death $(23 \%$ versus $5 \%$ ) compared with conservative treatment. ${ }^{15}$ However as Connolly et al, have addressed a treatment plan (deciding whether surgery is warranted) must be sorted via a comprehensive assessment of patient's condition rather than the severity of neurological symptoms alone. ${ }^{16}$

There have been reports of simultaneous caesarean section and craniotomy.

Our patient fulfilled the WHO criteria of maternal near miss as she was a case of eclampsia requiring ventillatory support, she also fulfilled the Gellers scoring criteria for near-miss having a score of 9 (score above 8 suggests near miss). ${ }^{5,17}$

In our patient eclampsia was managed with magnesium sulphate and immediate delivery of the foetus by caesarean section. Postoperatively CT scan of the brain was done as the patient had hemiparesis in the left side of the body which revealed an intracranial haemorrhage, as there was neurological deficit prompt decision was taken by the neurosurgeons for craniotomy, following which patient's neurological status improved markedly reiterating the benefit of surgical intervention as opposed to conservative management. This multidisciplinary approach in the management and care of the patient facilitated early recovery and subsequently prevented maternal death in this near miss case.

\section{CONCLUSION}

ICH although rare is an important cause of morbidity and mortality in pregnancy. Treatment decisions should be based on the same principles as those of non-pregnant patients with due cognizance of the influence that pregnancy has on certain conditions. A multidisciplinary approach including obstetricians, neurologists, neurosurgeons, physiotherapists and ICU physicians who should collaborate to provide high quality, timely and effective treatment. Early detection and treatment of preeclampsia might prevent all such complications altogether. Identification and reporting of such near miss cases is an important adjunct to aid in providing corrective measures and for developing strategies at grass root level to reduce maternal mortality.
Funding: No funding sources Conflict of interest: None declared

Ethical approval: Not required

\section{REFERENCES}

1. Tate J, Bushnell C. Pregnancy and stroke risk in women. Women's Health (London, England). 2011;7(3):363-74.

2. Liang ZW, Lin L, Gao WL, Feng LM. A clinical characteristic analysis of pregnancy-associated intracranial haemorrhage in China. Scie Reports. 2015;5:9509.

3. Yoshimatsu J, Ikeda T, Katsuragi S, Minematsu K, Toyoda K, Nagatsuka K, et al. Factors contributing to mortality and morbidity in pregnancy-associated intracerebral hemorrhage in Japan. J Obstet Gynaecol Res. 2014;40(5):1267-73.

4. James AH, Bushnell CD, Jamison MG, Myers ER. Incidence and risk factors for stroke in pregnancy and the puerperium. Obstet Gynecol. 2005;106(3):509-16.

5. World Health Organization. World Health Statistics 2011. Fact sheets. Geneva: WHO, 2009 and 2014. Available at: http://www.who.int/entity/gho/ publications/world_health_statistics?EN_WHS2011_ Ful 1.pdf.

6. Kitnner SJ, Stern BJ, Feeser BR, Hebel R, Nagey DA, Bliccholz DW, et al. Pregnancy and the risk of stroke. N Engl J Med. 1996;335(11):768-74.

7. Wittin AC, Friedman SA, Egermanter, Frangien AY, Sibai BM. Cardiovascular disorders complications in pregnancy beyond eclampsia. Am J Obstet Gynaecol. 1997:1139-45.

8. Liang CC, Chang SD, Lai SL, Hsieh CC, Chueh HY, Lee TH. Stroke complicating pregnancy and the puerperium. Eur J Neurol. 2006;13:1256-60.

9. Sharshar T, Lamy C, Mas JL. Incidence and causes of strokes associated with pregnancy and puerperium. A study in public hospitals of Ile de France. Stroke in Pregnancy Study Group. Stroke. 1995;26:930-6.

10. Bateman BT, Schumacher HC, Bushnell CD, PileSpellman J, Simpson LL, Sacco RL, et al. Intracerebral haemorrhage in pregnancy: Frequency, risk factors and outcome. Nuerol. 2006;67:424-9.

11. Kurth T, Kase CS, Berger K, Gaziano JM, Cook NR, Buring JE. Smoking and risk of haemorrhagic stroke in women. Stroke. 2003;4:2792-5.

12. Klatsky AL, Friedman GD, Sidney S, Kipp H, Kubo A, Armstrong MA. Risk of haemorrhagic stroke in Asian American ethnic groups. Nueroepidemiol. 2005;25:26-31.

13. Hameed AB, Shrivastava VK, Blair L, Wing DA. Intracranial haemorrhage in pregnancy AJP Rep. 2012;2(1):47-50.

14. Mendelow AD, Gregson BA, Fernandes HM. Early surgery versus initial conservative treatment in patients with spontaneous supratentorial haematomas in the International Surgical Trial in Intracerebral 
Haemorrhage: a randomised trial. Lancet. 2005;365:387-97.

15. Dias MS, Sekhar LN. Intracranial haemorrhage from aneurysms and arteriovenous malformations during pregnancy and the puerperium. Nuerosurg. 1990;27:855-65.

16. Connolly Jr ES, Rabinstein AA, Carhuapoma JR, Derdeyn CP, Dion J, Higashida RT, et al. Guidelines for the management of aneurysmal subarachnoid hemorrhage: a guideline for healthcare professionals from the American Heart Association/American Stroke Association. Stroke. 2012;43(6):1711-37.
17. Geller SE, Rosenberg D, Cox S, Brown M, Simonson L, Kilpatrick S. A scoring system identified near-miss maternal morbidity during pregnancy. J Clin Epidemiol. 2004;57:716-2.

Cite this article as: Kaundinya AP, Satia MN, Badhwar VR. Successful management of a near miss case of eclampsia with intracranial haemorrhage requiring craniotomy. Int J Reprod Contracept Obstet Gynecol 2019;8:5039-42. 